\title{
Understanding of human referential gestures is not correlated to humandirectedsocial behaviour in Labrador retrievers and German shepherd dogs
}

Ann-Sofie Sundman, Mia E Persson, Anna Grozelier, Lise-Lotte Halldén, Per J ensen and Lina Roth

The self-archived postprint version of this journal article is available at Linköping University Institutional Repository (DiVA):

http:// urn.kb.se/ resolve?urn=urn:nbn:se:liu:diva- 145542

N.B.: When citing this work, cite the original publication.

Sundman, A., Persson, M. E, Grozelier, A., Halldén, L., J ensen, P., Roth, L., (2017), Understanding of human referential gestures is not correlated to humandirectedsocial behaviour in Labrador retrievers and German shepherd dogs, Applied Animal Behaviour Science.

https:// doi.org/ 10.1016/j.applanim.2017.12.017

Original publication available at:

https:/ / doi.org/ 10.1016/j.applanim.2017.12.017

Copyright: Elsevier

http:// www.elsevier.com/

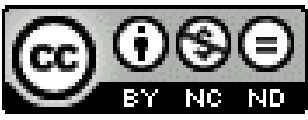




\section{Understanding of human referential gestures is not correlated to}

human-directed social behaviour in Labrador retrievers and German shepherd dogs

Ann-Sofie Sundman, Mia E. Persson, Anna Grozelier, Lise-Lotte Halldén, Per Jensen, Lina S V Roth*

AVIAN Behaviour Genomics and Physiology Group, IFM Biology, Linköping University, 58183

Linköping, Sweden

* Corresponding author: lina.roth@liu.se, phone number: +4613282611

Keywords: human-dog communication; human-directed social behaviour; pointing test; problemsolving test; German shepherd dogs; Labrador retrievers 


\begin{abstract}
Dogs are known to excel in interspecific communication with humans and both communicate with humans and follow human communicative cues. Two tests commonly used to test these skills are, firstly, the problem-solving paradigm, and, secondly, following human referential signals, for example pointing. The aim of the present study was to investigate whether dogs that seek more human contact in an unsolvable problem-solving paradigm also better understand human communicative cues in a pointing test. We also assessed between- and within-breed variation in both tests. 167 dogs were tested and were of the breeds German shepherd dog and Labrador retriever. The Labradors were separated into the two selection lines: common type (bred for show and pet) and field type (bred for hunting). A principal component analysis of behaviours during the problem solving revealed four components: Passivity, Experimenter Contact, Owner Contact and Eye Contact. We analysed the effect of these components on success rate in the pointing test and we found no effect for three of them, while a negative correlation was found for Owner Contact $\left(F_{(1,147)}=6.892 ; P=0.010\right)$. This was only present in common-typed Labradors. We conclude that the ability to follow a pointing cue does not predict the propensity for human-directed social behaviour in a problem-solving situation and suggest that the two tests measure different aspects of human-directed social behaviour in dogs.
\end{abstract}

\title{
1 Introduction
}

In recent years, social cognition in dogs has been intensely studied. It seems that dogs during domestication have acquired unique abilities for interspecific social behaviour with humans (Miklósi and Topál, 2013). Dogs recognize and interpret human communicative signals and also communicate with humans in a way that is not found to the same extent in their wild ancestor, the grey wolf (Canis lupus) (Hare et al., 2002; Miklósi et al., 2003), nor in human's phylogenetically close relatives chimpanzees (Pan troglodytes) and bonobos (P. paniscus) (Bräuer et al., 2006). In fact, dogs have been shown to behave more like human infants than wolves in response to human ostensive cues (Topál et al., 2009).

There are two commonly used ways to study interspecific social capabilities. Firstly, subjects' humandirected social behaviour is studied in a problem-solving paradigm, usually unsolvable, and secondly, subjects' skill to follow human communicative referential gestures is tested in a pointing test. In the first test type it has been shown that dogs readily communicate with humans through, for example, attention-seeking and attention-directing signals toward humans, sometimes called showing or helpseeking behaviour (Hare et al., 1998; Miklósi et al., 2000). In the second class of tests, dogs have been shown to have an understanding of human pointing gestures and are able to follow them to find food in an object-choice paradigm (Hare et al., 1998; Miklósi et al., 1998). It seems that the understanding of this cue cannot be explained by simple local enhancement (Hare et al., 1998; McKinley and Sambrook, 2000), and some research even suggests that dogs in fact understand the communicative intent of the sender (Szetei et al., 2003; Tauzin et al., 2015).

Interestingly, comparative studies have shown that wolves do not seek human contact to the same extent when faced with a problem (Miklósi et al., 2003; Udell, 2015; Heberlein et al., 2016) and dogs 
perform better in the pointing task than both wolves (Hare et al., 2002; Virányi et al., 2008) and chimpanzees (Kirchhofer et al., 2012). Also, there are studies indicating that the ancient, feralised dog breed the Australian dingo performs between that of wolves and modern dogs both in pointing understanding and spontaneous eye contact (Smith and Litchfield, 2010; Johnston et al., 2017). This suggests that these are behaviours that have been affected by domestication.

Not all dogs perform equally in these two tests, however. In both types of social interactions there are individual differences as well as differences between groups of dogs (Gácsi et al., 2009a). While primitive breeds, for example the New Guinea singing dog, also show interspecific communicative skills, documented breed differences show that selection can affect these abilities (Wobber et al., 2009; Passalacqua et al., 2011; Udell et al., 2014). For example, Wobber et al. (2009) showed that both historical working and non-working breeds performed above chance level in a pointing test, although dogs of working breeds performed more successfully than dogs of non-working breeds. However, the background of the dogs, for example the amount of training, might differ between breeds and this might have influenced the result. It is not known how recent selection has affected the interspecific communication in dogs. This can, for example, be studied in recently diverged breeds where types are selected for different purposes.

The fact that there are differences in human-directed communicative skills between breeds suggests that there is a genetic basis for these behaviours, which is a prerequisite for selection. Consistent with this, genetic studies have found moderate heritability estimates and identified candidate genes for human-directed social behaviour during problem solving (Hori et al., 2013; Persson et al., 2015; Persson et al., 2016). These skills are also affected by experiences during ontogeny such as training for different tasks (Marshall-Pescini et al., 2009). Additionally, pet dogs seem more skilled than shelter dogs which, presumably, have less human communication experience (Udell et al., 2010). It is thus not clear how much of the communicative skills that can be explained by ontogeny and how much by phylogeny.

We investigated whether these two communicative skills, to follow human gestures and to seek human contact, reflect a common underlying general ability for interacting with humans, perhaps as genetically correlated traits evolving during domestication. Alternatively, the two traits could be genetically unrelated, and selected independently of each other. To distinguish the two possibilities, we examined the correlation between the behaviour of dogs in each of the two experimental tests, firstly assessing the ability to follow human referential gestures, and secondly, the ability to seek human contact in a problem-solving situation. To investigate how these traits have been selected in different breeds we used both German shepherd and Labrador retriever dogs. Also, to investigate how these behaviours have been affected by recent selection criteria we compared two recently separated types of Labrador retriever, one selected for show and pet qualities and the other for hunting behaviour.

\section{Methods}


The study was approved by Linköping local Ethical committee of The Swedish National Board for Laboratory Animals (approval no. Lkp 85-07).

\subsection{Subjects}

A total of 167 dogs of the breeds Labrador retriever (Labrador) and German shepherd dog (GSD) participated in this study after their owners were recruited on a voluntary basis through social media. These two breeds were chosen because both are common breeds and they are of equal size. Both Labradors and GSDs were also recruited for participation in other studies. Due to noncompliance in the pointing test (participating in less than half of the choices; see description below) or failing the motivation test for the problem solving (see description below), 12 dogs were excluded from the analysis. Additionally, two Labradors were removed due to unknown ancestry. Out of the remaining dogs, 32 were GSDs ( 16 females and 16 males) and 121 were Labradors ( 63 females and 58 males). Labradors were further classified as either common type or field type based on titles (e.g. field-trial champion) of ancestors in their pedigrees. If ancestors for at least three generations back were bred for field work, the dogs were classified as field-type Labradors. If none of the ancestors had field titles, they were instead classified as common-type Labradors and most had ancestors with show titles. Most Labradors were clearly of one type or the other and no dogs with dubious or mixed ancestry were included in the study. Type classification was additionally confirmed by kennel information and physical phenotype. For pedigrees, Swedish Kennel Club's online registry was used (Hunddata, http://hundar.skk.se/hunddata/), and k9data.com (http://www.k9data.com/) with pedigrees of Labradors from other countries. Based on this analysis, 60 Labradors were classified as common type ( 35 females and 25 males) and 61 as field type ( 28 females and 33 males).

To obtain some background information about the dogs, dog owners also answered a questionnaire. They were asked the following: 'Is this your first dog?', 'Does your dog live together with other dogs?', 'How many hours do your dog on average spend alone each day?' and 'How many hours do you on average activate (walks, training etc.) your dog each day?'. Also, on a Likert scale from 0 to 4 , strongly disagree to strongly agree, they were asked the following: 'I got this dog because I wanted a nice companion dog', 'I got this dog because I wanted a dog good for training', 'I train often with my dog', 'I play often with my dog', 'I often correct my dog' and 'I often reward my dog with treat or play'. Labrador owners had the additional question 'I often train fetch with my dog'.

The mean age (years) of the GSDs was $3.34 \pm 0.427$ ( \pm SEM) and of the Labradors $2.43 \pm 0.195$. Within the Labrador breed, the mean age of the common type was $2.10 \pm 0.228$ and of the field type $2.75 \pm$ 0.311 .

\subsection{Experimental design}

Data was collected between August and November 2014. Tests were carried out at seven different locations in Sweden. All dogs included in the analyses participated first in a problem-solving test followed by a pointing test. Both tests were video recorded with a full-HD camcorder (Canon Legria 
HF G25) for later analysis. The experiments were performed in a marquee measuring $3 \times 3 \mathrm{~m}$ in order to achieve a uniform environment at the different locations. Three of its sides had canvas walls and the fourth was closed off with a fence (Figure 1).

The treats used were pieces of Frolic ${ }^{\circledR}$ Complete, unless the dog had allergies and the owner brought approved treats. Prior to the testing a motivation test was performed to assure that the dog was motivated to eat the treat. The plate used was similar to the compartments used in the problemsolving test, but did not have a lid (see description below).

There were two persons testing approximately half the dogs each as well as analysing the videos. Tests and observational analysis were therefore coordinated by the two experimenters, and also by two supervising test leaders, to ensure a high accordance between them. Both experimenters and test leaders were female.

\subsubsection{Problem-solving test}

The problem-solving paradigm we used has previously been described in detail by Persson et al. (2015) and is shown in Figure 1A. The test apparatus was a plate with three identical compartments covered by Plexiglas lids, each with six $0.5 \mathrm{~cm}$ odour holes. All compartments contained treats. Two lids could easily be slid to the side and thereby opened while the lid in the middle was screwed on and could not be opened.

The dog owner held the dog in the front right corner of the marquee while the experimenter placed the test apparatus on the ground in the middle of the back side of the marquee, approximately 40 $\mathrm{cm}$ from the wall and 2 metres from the dog. The experimenter placed herself in the front left corner and signalled to the owner to release the dog, after which the owner and experimenter remained passive and facing the apparatus throughout the test. If the dog escaped the marquee under the canvas, it was quickly called back inside and the owner went back to being passive. If the dog had not opened any of the compartments after 1 minute, the experimenter slid the two lids that could be opened halfway to the side and then went back to the corner. The total test duration was 3 minutes. Afterwards, the dog was leashed and apparatus removed from the marquee.

Behaviours in the problem-solving test were continuously recorded using the computer program The Observer ${ }^{\circledR}$ XT 10 by Noldus. The ethogram, adapted from Persson et al. (2015), is shown in Table 1. For most behaviour items we recorded frequency, duration or latency (Table 1). Additionally, the time it took the dog to solve the two solvable parts of the task (time until it consumed the treats) was noted and the number of direct transitions between owner and test apparatus, experimenter and test apparatus and owner and experimenter were recorded. Also, a body posture score and intensity score were given according to scales in Table 2 and Table 3, respectively. 


\subsubsection{Pointing test}

Directly following the problem-solving test the pointing test was performed (Figure 1B). Two opaque upturned black buckets were used as targets. Both buckets were rubbed with a treat before starting the experiment to avoid the dog using olfactory cues when choosing. Prior to the test, the dogs were given a treat three times, alternating the buckets, paired with the cue "varsågod" ("go ahead") from the experimenter. All dogs were familiar with the cue.

For the testing, a momentary distal pointing cue was used. The owner held the dog by its collar in an opening of the fence in the middle front of the marquee and the experimenter placed herself in the middle back of the marquee. Out of sight of the dog, the experimenter put a treat in one of the buckets with her back to the dog and then turned around and sought eye contact with the dog. If needed the experimenter made a small noise or called the dog's name to get its attention. The buckets were placed on the ground approximately $30 \mathrm{~cm}$ in front of the experimenter and $110 \mathrm{~cm}$ from each other. The distance to the dog was approximately 2.5 metres. After eye contact was established the experimenter performed the pointing cue by extending her arm toward the target bucket containing a treat. She held the cue for 2 seconds before bringing the arm back to neutral position with arms along her sides. The cue "varsågod" was then given by the experimenter while still having eye contact with the dog and the dog was released to make its choice. The experimenter stood still in neutral position, making sure not to make movements to avoid a Clever Hans effect. The owners were instructed to keep their gaze on their feet or close their eyes and did not see the direction of the pointing. At the end of each trial the dog was called back to its owner and a new trial started. 20 trials were performed with a break of approximately 1 minute after ten trials. The correct direction, either the left or the right bucket, was presented in a predetermined pseudo-random order with no more than two correct choices in the same direction in a row and with equal numbers to the left and the right. Trials were marked either as correct, incorrect or as "no choice". The dog was considered to have made a choice when its nose was within a head length of a bucket. If the dog did not make a choice within 3 seconds, the trial was marked as "no choice". Immediately after a choice was made, the experimenter removed the other bucket.

\subsection{Statistical analysis}

A principal component analysis (PCA) was performed on the behavioural data from the problemsolving test to reduce the number of variables. For the proximity measurements, durations were used and for human contact measurements of both frequency and duration were used. All dogs completing the test $(n=153)$ were used in the analysis. The sampling adequacy was as follows: Bartlett's sphericity test $\chi^{2}=1586.624, \mathrm{df}=153, \mathrm{p}<0.001 ; \mathrm{KMO}: 0.752$. The PCA solution was rotated with varimax rotation. The individual PC scores were then used in the following analyses.

The pointing test was analysed in two ways. Firstly, we analysed individual performance. To do this, we used a two-tailed exact binominal test for the number of correct choices out of the total number of choices. This was done for each dog separately and the dogs were either considered to have passed or failed (binomial significance; $p<0.05$ ). To compare the breeds and the types, the result 
(pass/fail) was used in a Pearson chi-square test. Secondly, we used the frequency of correct choices. This was calculated as the percentage of correct choices out of the total number of choices performed by the dog. With Student's t-tests we analysed if the dogs performed above chance level. This was done separately for the total number of dogs and within breeds and types. Moreover, to analyse for possible learning effects during the test session, we compared the frequency of correct choices during the first set of ten pointings to the second set with a paired-samples $T$ test. The trials where the dogs made no choice were regarded as non-valid and therefore not included in the analysis.

To analyse the effect of breed and type on the components from the problem-solving test and the frequency of correct choices in the pointing test, univariate general linear models (GLM) were used. Age (covariate) and sex (fixed effect) were added to the models to account for possible effects of these factors. Additionally, GLMs were used to analyse the effect of the scores from the principal components derived from the problem-solving test on pointing performance. Frequency of correct choices in the pointing test was used as dependent variable and component scores were entered as covariates. Type (GSD, common Labrador and field Labrador) and sex (fixed effects) and age (covariate) were included in the models. For all GLMs, model simplification was performed by backward elimination of insignificant interactions (breed and type comparison) and interactions and main effects except for components (components effect on pointing performance).

Lifestyle questions were compared between breeds and types with an independent-samples MannWhitney $\mathrm{U}$ test. Durations and scores on the scales were correlated to the scores on the principal components from the problem-solving test and on pointing performance using Spearman's rank order correlation.

The software IBM SPSS statistics 24 was used for all statistical analyses and a significance level of at least 0.05 was used. Results are presented as mean \pm SEM.

\section{Results}

\subsection{Problem-solving test}

From the PCA performed on the behavioural variables in the problem-solving test, four components were retained based on an evaluation of scree plot and eigenvalues. These components explained $63.55 \%$ of the total variance of the included behavioural variables. The PCA loadings are presented in Table 4. Variables with loadings higher than 0.4 were considered relevant for the component and all variables reached this criteria for at least one component. Components were labelled based on relevant variables. Relevant for the first component were interactions with and time spent in proximity of the test setup (negative), and time until solved, intensity and body posture score (positive). This component was labelled "Passivity". For the second component, proximity and physical contact with the experimenter loaded high and it was therefore labelled "Experimenter Contact". The third component had high loadings for owner proximity and physical contact and was 
labelled "Owner Contact". Eye contact with both owner and experimenter loaded on the fourth component and this was labelled "Eye Contact". From this point, the components will be referred to by these labels.

Breed had a significant effect on the scores from all behaviour components (Figure 2). The GSDs scored higher on Passivity $\left(\mathrm{F}_{(1,149)}=36.719 ; \mathrm{P}<0.001\right)$ as well as on Experimenter Contact and Owner Contact $\left(F_{(1,148)}=6.083 ; P=0.015\right.$ and $F_{(1,145)}=12.952 ; P<0.001$, respectively) compared to the Labrador, while the Labrador scored higher on Eye Contact $\left(F_{(1,149)}=4.307 ; P=0.040\right)$. For Experimenter Contact, there was an interaction between breed $x$ age $\left(F_{(1,148)}=5.775 ; P=0.017\right)$. While the behaviour did not change with age in the Labrador it tended to decrease with age in the $\operatorname{GSDs}\left(F_{(1,28)}=2.938 ; P=0.098\right)$. For Owner Contact, there was a significant effect of age and it decreased with age $\left(F_{(1,145)}=5.570 ; P=0.020\right)$. Furthermore, for Owner Contact, there were significant interactions between breed $x$ age $\left(F_{(2,145)}=8.963 ; P=0.003\right)$, breed $x \operatorname{sex}\left(F_{(1,145)}=7.861\right.$; $P=0.006)$ and breed $x$ sex $x$ age $\left(F_{(1,145)}=5.168 ; P=0.003\right)$. As with Experimenter Contact, Owner Contact did not change with age in the Labrador but it decreased with age in the GSDs $\left(F_{(1,28)}=7.008\right.$; $P=0.039$ ). Regarding the breed $x$ sex interaction, the difference in means was larger between males and females in GSDs than in Labradors, however, the difference was not in itself significant.

When analysing the differences within the Labrador between common and field type, we found that type had a significant effect on Owner Contact $\left(F_{(1,114)}=9.074 ; P=0.003\right)$ and Eye Contact $\left(F_{(1,116)}=14.582 ; P<0.001\right)$ where the field type scored higher on both of these components (Figure 3). There was a significant interaction between type $x$ age for Experimenter Contact $\left(F_{(1,116)}=4.632 ; P\right.$ $=0.033)$ as well as Eye Contact $\left(F_{(1,116)}=4.456 ; P=0.037\right)$. Scores for Experimenter Contact increased with age within the common type $\left(F_{(1,57)}=4.547 ; P=0.037\right)$ while there was no difference with age in the field type. For Eye Contact, scores increased with age within the common type $\left(F_{(1,56)}=7.755 ; P\right.$ $=0.007)$ while it did not change in field type. For Owner Contact, there was an interaction between type $x$ sex $x$ age $\left(F_{(3,114)}=7.387 ; P<0.001\right)$. Within the common type but not the field type there was a significant interaction between age $x$ sex for this component $\left(F_{(1,56)}=12.607 ; P=0.001\right)$. In common typed females, Owner Contact increased with age while no difference was observed in males.

\subsection{Pointing test}

The mean proportion of successful choices for all dogs was $0.690 \pm 0.012$ and this significantly differed from 0.5 , the expected chance level $\left(t_{(152)}=15.420, p<0.001\right)$. This was also true when separating the two breeds (GSDs: $0.632 \pm 0.025 ; \mathrm{t}_{(31)}=5.187, \mathrm{p}<0.001$, Labradors: $0.706 \pm 0.152$; $\mathrm{t}_{(121)}=14.917, \mathrm{p}<0.001$ ), as well as when analysing the two Labrador types separately (common: $0.690 \pm 0.158 ; \mathrm{t}_{(59)}=9.318, \mathrm{p}<0.001$, field: $\left.0.720 \pm 0.0185 ; \mathrm{t}_{(61)}=11.923, \mathrm{p}<0.001\right)$.

The number of individuals passing versus failing the pointing test according to significance in the binomial test is presented in Figure 4. There was a significant difference between the breeds and 
more Labradors than GSDs passed the test $\left(X^{2}(1,153)=6.622, p=0.010\right)$. Between the Labrador types there was no difference between common and field $\left(X^{2}{ }_{(1,121)}=2.413, p=0.120\right)$.

Lastly, there was no difference between the mean frequency of success for all dogs in the first set $(0.679 \pm 0.015)$ compared to the second set $(0.697 \pm 0.015)\left(t_{(152)}=-1.184, p=0.238\right)$, indicating no learning took place during the test.

\subsection{Pointing versus problem solving}

The relationship between pointing success and scores on each of the four problem-solving principal components is presented in Figure 5 together with $\mathrm{R}^{2}, \mathrm{~F}$ and $\mathrm{P}$ values. Owner Contact scores had a significant effect on pointing performance and with higher Owner Contact scores, pointing performance decreased $\left(F_{(1,147)}=6.892 ; P=0.010\right)$. There was, however, also an interaction between type $\times$ Owner Contact $\left(\mathrm{F}_{(2,147)}=3.081 ; \mathrm{P}=0.049\right)$. While Owner Contact affected pointing performance in common-type Labradors, it did not have an effect in GSDs or field Labradors. Scores on Passivity, Experimenter Contact and Eye Contact did not affect pointing performance.

There were few significant differences between breeds and types in the background of the dogs. These are summarised in Supplementary Table S1. Some of the background information also correlated with the results in the behavioural tests and these correlations are summarised in Supplementary Table S2.

\section{Discussion}

Our main aim was to investigate if the skill of following human referential cues in the pointing test and the willingness to seek human contact during problem solving reflects a common sociability with humans. The result of our study suggests little correlation between the abilities and thus that the traits seems to have been selected independently. Furthermore, we found breed differences in the performance in the pointing test as well as in human contact-seeking behaviour and within-breed differences in the latter.

Both the pointing test and the problem-solving paradigm have previously been used in a range of studies to study interspecific communication between dogs and humans. The fact that dogs excel at following human referential cues and are quick to seek human contact, especially eye contact, when faced with a problem, in comparison to wolves, have been suggested to be effects of domestication (Hare et al., 2002; Miklósi and Topál, 2013). In this study, we investigated the link between pointing performance and human-directed social behaviour displayed during a problem-solving test in order to evaluate whether both reflect an underlying sociability towards humans. This does not, however, seem to be the case. We found no correlations between pointing performance and problem-solving scores on principle components Passivity, Experimenter Contact or Eye Contact. However, there was an unexpected negative correlation between pointing performance and scores on Owner Contact 
during the problem solving, and an interaction between breed type and Owner Contact. This correlation was only present in common-typed Labradors. The negative correlation might be a consequence of dogs showing higher Owner Contact being less willing to leave their owner and follow instructions of a stranger (the pointing cue), but the common Labrador has previously been shown to be the most social towards strangers of the three groups (Svartberg, 2006; Sundman et al., 2016). We have no explanation for this unexpected negative correlation, but it generally adds to the overall results, that the ability of following a pointing cue does not predict the propensity for helpseeking behaviour in a problems-solving situation. In a recent study by MacLean et al. (2017) a test battery of social cognition experiments was performed and, consistent with our results, behaviour in the unsolvable problem test and the ability to follow referential cues loaded on different factors in a factor analysis and on different clusters in a dendogram.

It has been argued that human-directed social behaviour during the unsolvable problem test rather is a measure of persistence than social cognition. For example, Marshall-Pescini et al. (2017) compared gazing in wolves and dogs using persistence, that is time interacting with the test setup, as an explanatory factor in their statistical model. When doing this, they found no group difference while there was a difference when persistence was removed. Studies also show a correlation between persistence and eye-contact duration (negative) and latency to look back (positive) (Brubaker et al., 2017; Marshall-Pescini et al., 2017). In contrast, in the present study the group that shows the highest Passivity (lowest persistence) during problem solving shows lowest Eye Contact. The fact that we did not find convincing correlations to the pointing test may support the notion that the unsolvable problem test, to at least some degree, measures something else than social behaviour. Future research need to more clearly disentangle persistent problem solving from social motivation. Additionally, motivation for treats may differ between dogs and influence the dog's behaviour in both the pointing test and problem-solving test. A dog with a higher motivation is supposedly more willing to engage in the task and less likely to be distracted by its surroundings.

In the two tests performed, differences were found between breeds as well as between breed types within the Labrador group. In the pointing test, all dogs of both breeds and selection lines performed above chance on a group level, agreeing with previous research (for review, see Kaminski and Nitzschner, 2013). We did, however, find a difference between GSDs and Labradors, where the latter performed with higher success. While Dorey et al. (2009) found no differences between breed groups in a meta-analysis, other studies report that breed-specific traits do have an effect in the pointing test. For example, historical function of the breeds seems to matter. Wobber et al. (2009) found that traditional working breeds perform better than non-working breeds, and Gácsi et al. (2009b) showed that dogs from cooperative working breeds perform better than independent ones. The latter also balanced the groups for housing condition, daily interaction duration between owner and dog and training to avoid experience effects on the results (Gácsi et al., 2009b). Since both of the breeds in the present study are historically cooperative working breeds, this cannot explain the difference found, although, it can be argued that the historical working task of GSDs is more independent from humans than that of the hunting retriever (Jakovcevic et al., 2010). In contrast, Udell et al. (2014) argue that a selection related exaggeration of the predatory motor sequence influences pointing success positively while an inhibition influences it negatively. Although, that study 
only includes three breeds. The Labrador, being a retriever, could be considered to have a more exaggerated predatory motor sequence than the GSD, a herding and guardian dog (Coppinger and Coppinger, 1996), but our results are based on too small a breed selection to either verify or reject the suggestions of Udell et al (2014). As previously mentioned, earlier research shows that Labradors are more social towards strangers than GSDs (Svartberg, 2006), which may influence their performance in the pointing test since the experimenter is a new acquaintance and dogs in general follow the cues of a trustworthy person to a higher degree (Takaoka et al., 2015).

Between the two selection types of Labradors there was no difference in pointing performance. Recent selection of Labradors has separated the breed into two types, one bred for pet/conformation and the other bred with the original function as a gundog in mind. This separation in the breed is very clear both when studying pedigrees, with exclusively field titles in one type versus show titles in the other, and specific kennels keeping to one type, as well as the morphology of the dogs, where the common typed is of a more sturdy build than the slim, high-legged field type. Considering that the field type is indeed a highly cooperative working dog a difference in the pointing performance was expected. However, since this was not found, it seems that the high ability to follow human gestures is robust despite recent new selection criteria.

In the problem-solving test we found differences both between the breeds and between the selection lines. The principal components from the problem-solving test in the present study, namely Passivity, Experimenter Contact, Owner Contact and Eye Contact, are similar to what was previously found in beagles with the same test (Persson et al., 2015). The advantage of this specific test is that neither training nor consecutive trials are required, in contrast to many other unsolvable problem tests used to study human-directed social behaviour. Results showed that the GSDs scored higher on Passivity and on Experimenter and Owner Contact, while the Labradors showed more Eye Contact. This is in concurrence with previous research using the same breeds where retrievers, including Labradors, gazed more at the human during problem solving than GSDs did (Jakovcevic et al., 2010). Within the Labrador breed, we found that the field type scored higher on both Owner Contact and Eye Contact compared to the common type. Gazing more at humans might reflect a higher cooperation in Labradors in general in comparison to GSDs, as discussed by Jakovcevic et al. (2010), and in the field type specifically. Previous research has revealed a significant genetic component to the performance in this test, identifying putative candidate genes affecting the behaviour (Persson et al., 2015; Persson et al., 2016). Hence, differences due to selection are not unexpected, and future research should attempt to identify the causative genes underlying this.

Additionally, as discussed above, persistence and food motivation may affect dogs' behaviour during the tests and it is possible that these also differ between breeds and selection lines. Indeed, Raffan et al. (2015) investigated among other things food motivation and the gundog group, predominantly Labradors, scored highest when compared to other breed groups. 
While we do find differences between breeds and breeding lines within a breed, it is important to point out that we have not controlled for possible effects of lifetime experiences. We did find some systematic differences in this respect, and these appeared to affect our results to a certain extent. Hence, the results should be interpreted with some care. There might be consistent breed differences in what the dogs experience during life and previous studies have found that experience may affect human-directed communicative skills (Marshall-Pescini et al., 2008; Marshall-Pescini et al., 2009). Indeed, Marshall-Pescini et al. (2016) found that both training and breed group had an effect on gazing behaviour during problem solving. Therefore, we suggest that future studies should account for lifestyle and experience of the dogs to be able to give a clearer picture on selection versus environmental effects.

\section{Conclusion}

Our findings show that both German shepherds and Labradors perform well over chance level in the pointing test, and their behaviour towards humans in a problem-solving test is similar to what has been shown in previous research on dogs. In both tests, there were some behavioural differences between breeds and breed types, indicating that human-directed social behaviour may have been affected by both long- and short-term selection goals. There were no positive correlations between pointing test performance and human-directed contact behaviour during problem solving. We therefore suggest that the two tests measure different independently selected aspects of humandirected social behaviour.

\section{Acknowledgements}

We would like to thank the dedicated dog owners that kindly allowed their dogs to participate in this study. The project was funded by an Advanced Research Grant from the European Research Council (ERC), project 322206 "GENEWELL". 


\section{References}

Brubaker, L., Dasgupta, S., Bhattacharjee, D., Bhadra, A., Udell, M.A.R., 2017. Differences in problemsolving between canid populations: Do domestication and lifetime experience affect persistence? Anim. Cogn. 20, 717-723.

Bräuer, J., Kaminski, J., Riedel, J., Call, J., Tomasello, M., 2006. Making inferences about the location of hidden food: social dog, causal ape. J. Comp. Psychol. 120, 38.

Coppinger, R., Coppinger, L., 1996. Biologic Bases of Behavior of Domestic Dog Breeds, in: Voirth, V.L., Borchelt, P.L. (Eds.), Readings in Companion Animal Behavior, Veterinary Learning Systems, Trenton, New Jersey, pp. 9-18.

Dorey, N.R., Udell, M.A., Wynne, C.D., 2009. Breed differences in dogs sensitivity to human points: A meta-analysis. Behav Processes 81.

Gácsi, M., Kara, E., Belényi, B., Topál, J., Miklósi, Á., 2009a. The effect of development and individual differences in pointing comprehension of dogs. Anim. Cogn. 12, 471-479.

Gácsi, M., McGreevy, P., Kara, E., Miklósi, Á., 2009b. Effects of selection for cooperation and attention in dogs. Behav Brain Funct 5, 31.

Hare, B., Brown, M., Williamson, C., Tomasello, M., 2002. The domestication of social cognition in dogs. Science 298, 1634-1636.

Hare, B., Call, J., Tomasello, M., 1998. Communication of food location between human and dog (Canis familiaris). Evol. Commun. 2, 137-159.

Heberlein, M.T.E., Turner, D.C., Range, F., Virányi, Z., 2016. A comparison between wolves, Canis lupus, and dogs, Canis familiaris, in showing behaviour towards humans. Anim. Behav. 122, 59-66. Hori, Y., Kishi, H., Inoue-Murayama, M., Fujita, K., 2013. Dopamine receptor D4 gene (DRD4) is associated with gazing toward humans in domestic dogs (Canis familiaris).

Jakovcevic, A., Elgier, A.M., Mustaca, A.E., Bentosela, M., 2010. Breed differences in dogs' (Canis familiaris) gaze to the human face. Behav. Processes 84, 602-607.

Johnston, A.M., Turrin, C., Watson, L., Arre, A.M., Santos, L.R., 2017. Uncovering the origins of doghuman eye contact: dingoes establish eye contact more than wolves, but less than dogs. Anim.

Behav. 133, 123-129.

Kaminski, J., Nitzschner, M., 2013. Do dogs get the point? A review of dog-human communication ability. Learn. Motiv. 44, 294-302.

Kirchhofer, K.C., Zimmermann, F., Kaminski, J., Tomasello, M., 2012. Dogs (Canis familiaris), but not chimpanzees (Pan troglodytes), understand imperative pointing. PLoS. ONE 7, e30913.

MacLean, E.L., Herrmann, E., Suchindran, S., Hare, B., 2017. Individual differences in cooperative communicative skills are more similar between dogs and humans than chimpanzees. Anim. Behav. 126, 41-51.

Marshall-Pescini, S., Frazzi, C., Valsecchi, P., 2016. The effect of training and breed group on problemsolving behaviours in dogs. Anim. Cogn. 19, 571-579.

Marshall-Pescini, S., Passalacqua, C., Barnard, S., Valsecchi, P., Prato-Previde, E., 2009. Agility and search and rescue training differently affects pet dogs' behaviour in socio-cognitive tasks. Behav. Processes 81, 416-422.

Marshall-Pescini, S., Rao, A., Virányi, Z., Range, F., 2017. The role of domestication and experience in 'looking back'towards humans in an unsolvable task. Sci Rep 7. 
Marshall-Pescini, S., Valsecchi, P., Petak, I., Accorsi, P.A., Previde, E.P., 2008. Does training make you smarter? The effects of training on dogs' performance (Canis familiaris) in a problem solving task.

Behav. Processes 78, 449-454.

McKinley, J., Sambrook, T.D., 2000. Use of human-given cues by domestic dogs (Canis familiaris) and horses (Equus caballus). Anim. Cogn. 3, 13-22.

Miklósi, Á., Kubinyi, E., Topál, J., Gácsi, M., Virányi, Z., Csányi, V., 2003. A simple reason for a big difference: wolves do not look back at humans, but dogs do. Curr. Biol. 13, 763-766.

Miklósi, A., Polgárdi, R., Topál, J., Csányi, V., 2000. Intentional behaviour in dog-human

communication: an experimental analysis of "showing" behaviour in the dog. Anim. Cogn. 3, 159-166.

Miklósi, Á., Polgárdi, R., Topál, J., Csányi, V., 1998. Use of experimenter-given cues in dogs. Anim.

Cogn. 1, 113-121.

Miklósi, Á., Topál, J., 2013. What does it take to become 'best friends'? Evolutionary changes in canine social competence. Trends Cogn Sci 17, 287-294.

Passalacqua, C., Marshall-Pescini, S., Barnard, S., Lakatos, G., Valsecchi, P., Prato Previde, E., 2011. Human-directed gazing behaviour in puppies and adult dogs, Canis lupus familiaris. Anim. Behav. 82, 1043-1050.

Persson, M.E., Roth, L.S., Johnsson, M., Wright, D., Jensen, P., 2015. Human-directed social behaviour in dogs shows significant heritability. Genes Brain Behav 14, 337-344.

Persson, M.E., Wright, D., Roth, L.S., Batakis, P., Jensen, P., 2016. Genomic regions associated with interspecies communication in dogs contain genes related to human social disorders. Sci Rep 6.

Raffan, E., Smith, S.P., O'Rahilly, S., Wardle, J., 2015. Development, factor structure and application of the Dog Obesity Risk and Appetite (DORA) questionnaire. PeerJ 3, e1278.

Smith, B.P., Litchfield, C.A., 2010. Dingoes (Canis dingo) can use human social cues to locate hidden food. Anim. Cogn. 13, 367-376.

Sundman, A.S., Johnsson, M., Wright, D., Jensen, P., 2016. Similar recent selection criteria associated with different behavioural effects in two dog breeds. Genes Brain Behav 15, 750-756.

Svartberg, K., 2006. Breed-typical behaviour in dogs - Historical remnants or recent constructs? Appl. Anim. Behav. Sci. 96, 293-313.

Szetei, V., Miklósi, Á., Topál, J., Csányi, V., 2003. When dogs seem to lose their nose: an investigation on the use of visual and olfactory cues in communicative context between dog and owner. Appl.

Anim. Behav. Sci. 83, 141-152.

Takaoka, A., Maeda, T., Hori, Y., Fujita, K., 2015. Do dogs follow behavioral cues from an unreliable human? Anim. Cogn. 18, 475-483.

Tauzin, T., Csík, A., Kis, A., Topál, J., 2015. What or where? The meaning of referential human pointing for dogs (Canis familiaris). J. Comp. Psychol. 129, 334.

Topál, J., Gergely, G., Erdőhegyi, Á., Csibra, G., Miklósi, Á., 2009. Differential sensitivity to human communication in dogs, wolves, and human infants. Science 325, 1269-1272.

Udell, M.A., 2015. When dogs look back: inhibition of independent problem-solving behaviour in domestic dogs (Canis lupus familiaris) compared with wolves (Canis lupus). Biol. Lett. 11, 20150489. Udell, M.A.R., Dorey, N.R., Wynne, C.D.L., 2010. The performance of stray dogs (Canis familiaris) living in a shelter on human-guided object-choice tasks. Anim. Behav. 79.

Udell, M.A.R., Ewald, M., Dorey, N.R., Wynne, C.D.L., 2014. Exploring breed differences in dogs (Canis familiaris): does exaggeration or inhibition of predatory response predict performance on humanguided tasks? Anim. Behav. 89, 99-105. 
Virányi, Z., Gácsi, M., Kubinyi, E., Topál, J., Belényi, B., Ujfalussy, D., Miklósi, Á., 2008. Comprehension of human pointing gestures in young human-reared wolves (Canis lupus) and dogs (Canis familiaris). Anim. Cogn. 11, 373-387.

Wobber, V., Hare, B., Koler-Matznick, J., Wrangham, R., Tomasello, M., 2009. Breed differences in domestic dogs'(Canis familiaris) comprehension of human communicative signals. Interact. Stud 10, 206-224. 


\section{Figures}

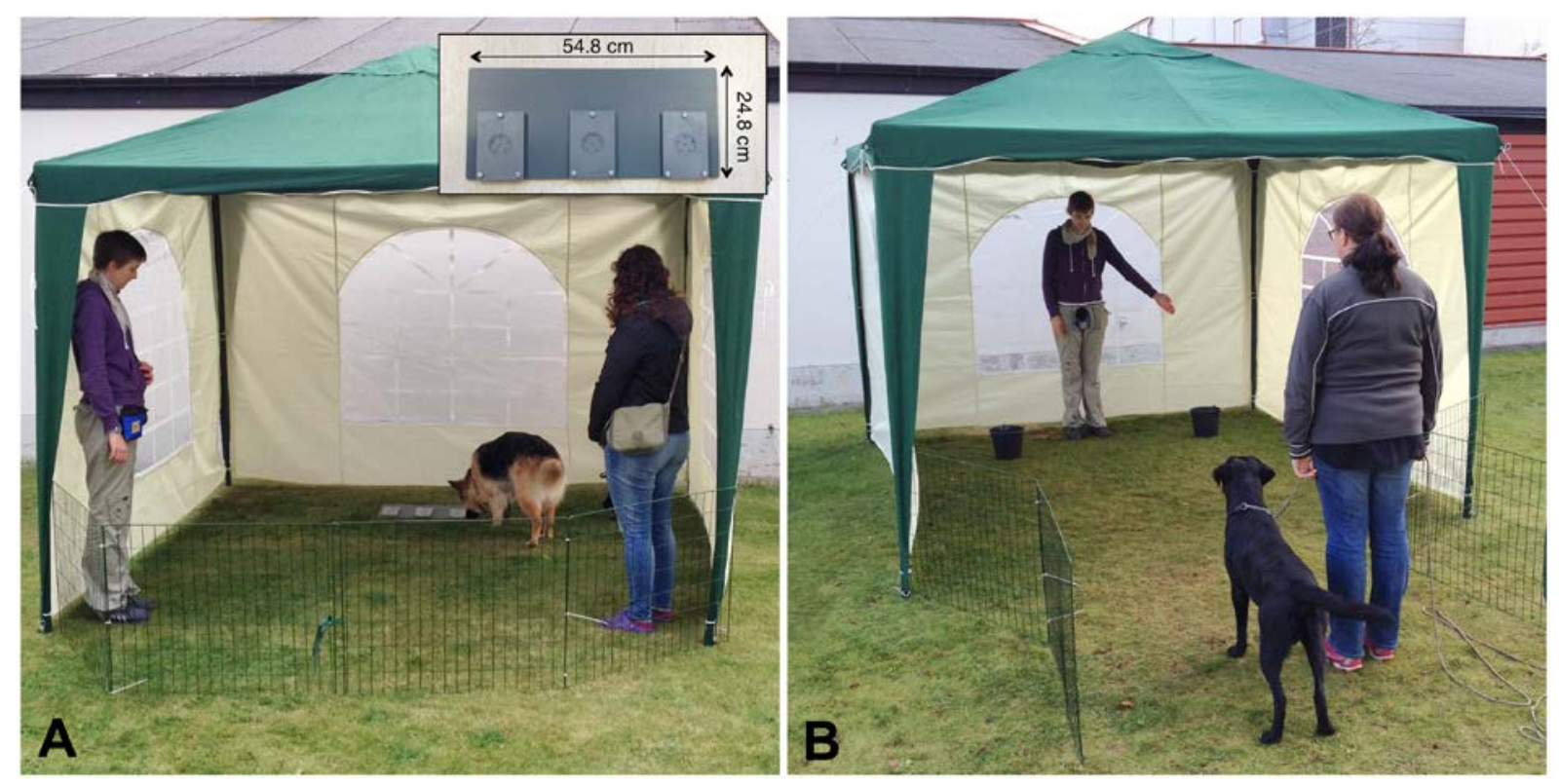

Figure 1. The experimental setup for $A$ ) the problem-solving test and $B$ ) the pointing test. 


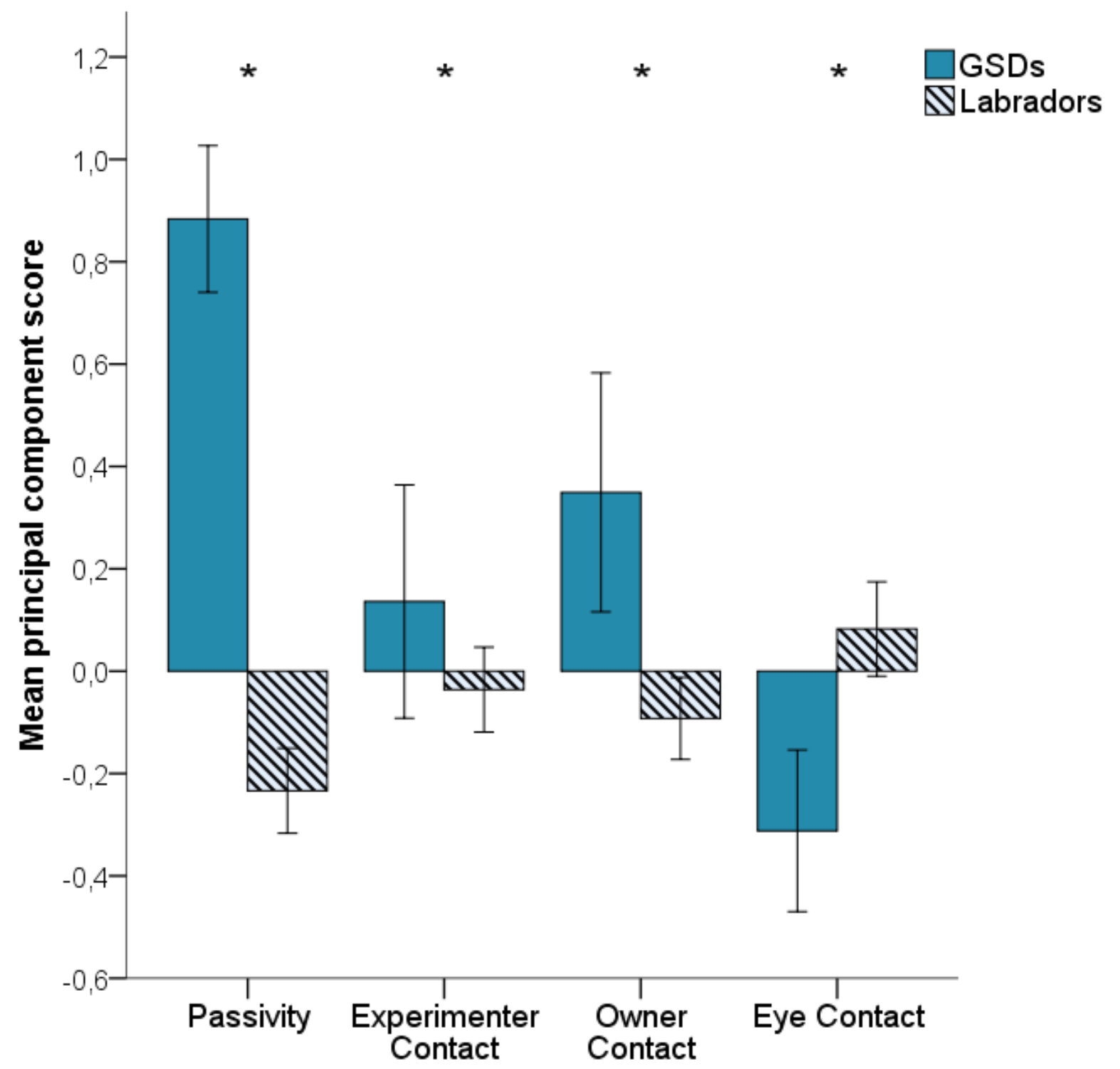

Figure 2. Breed differences between German shepherd dogs (GSDs) and Labrador retrievers in the problem-solving test.

$*=<0.05$ 


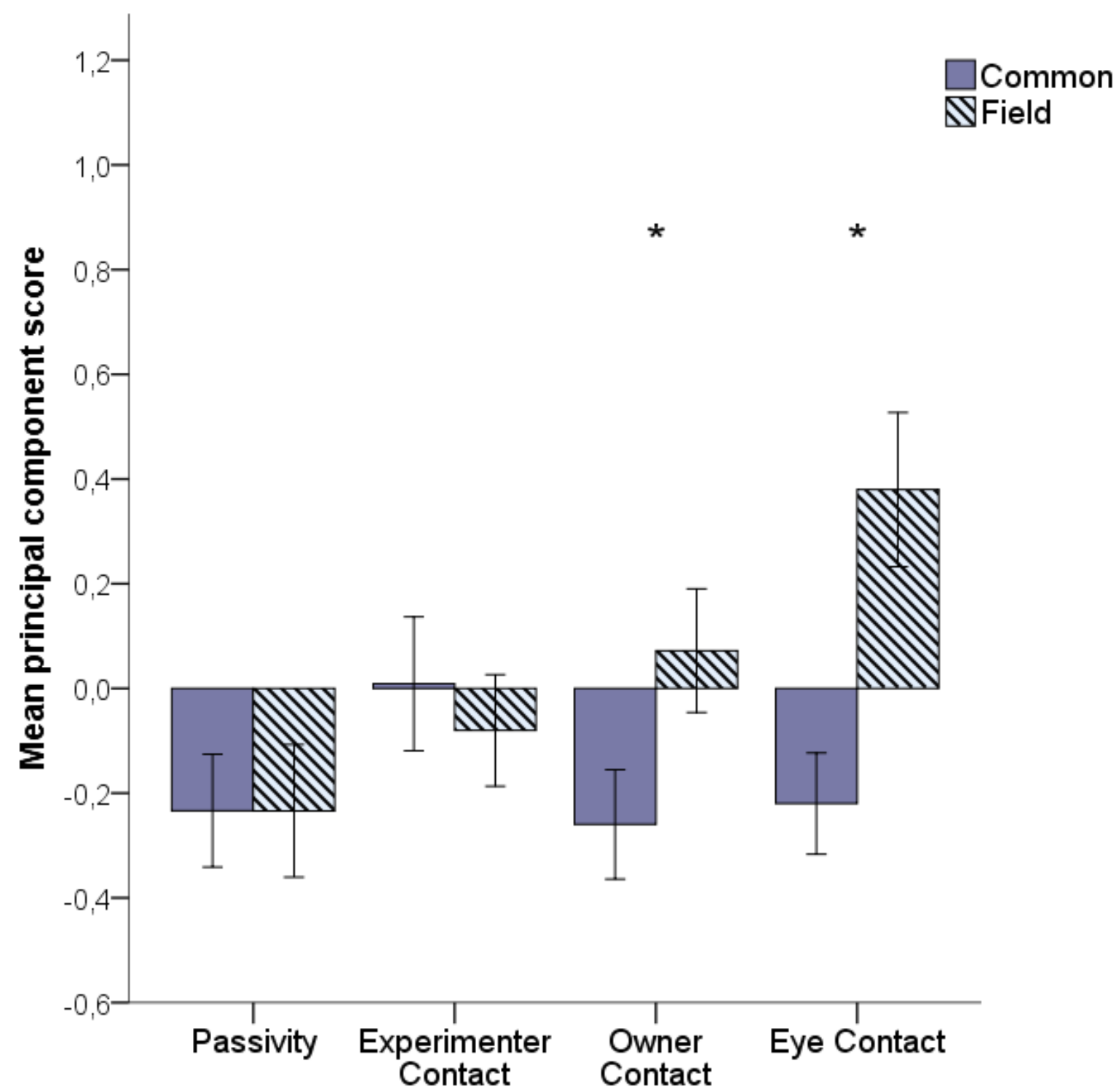

Figure 3. Differences between common-type Labrador retrievers and field-type Labrador retrievers in the problem-solving test.

$*=<0.05$ 


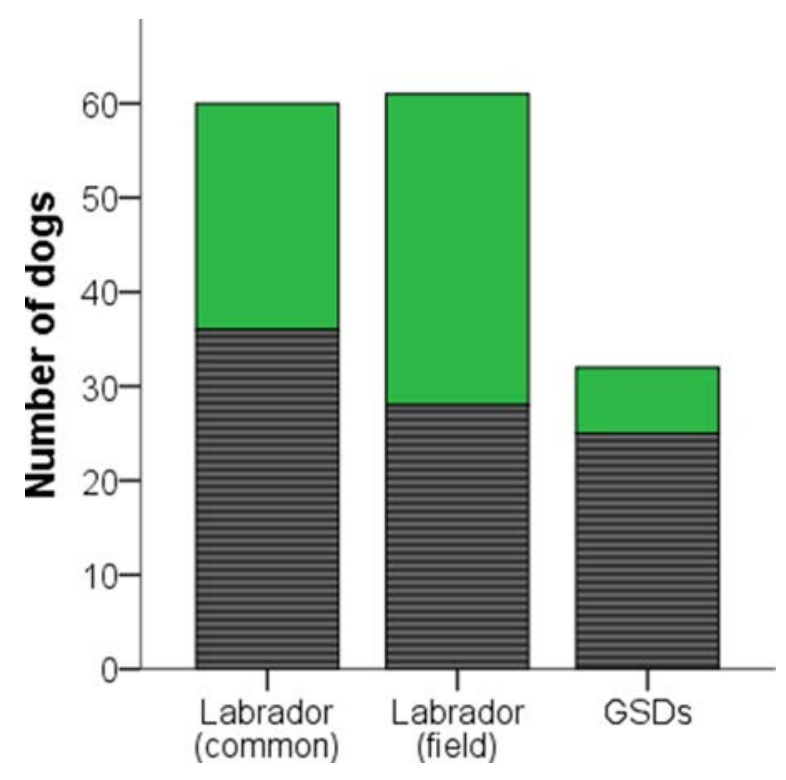

Figure 4. The number of dogs passing (solid) versus failing (striped) the pointing test for Labrador retrievers of common and field type and for German shepherd dogs (GSDs) according to binominal test $(p<0.05)$. 

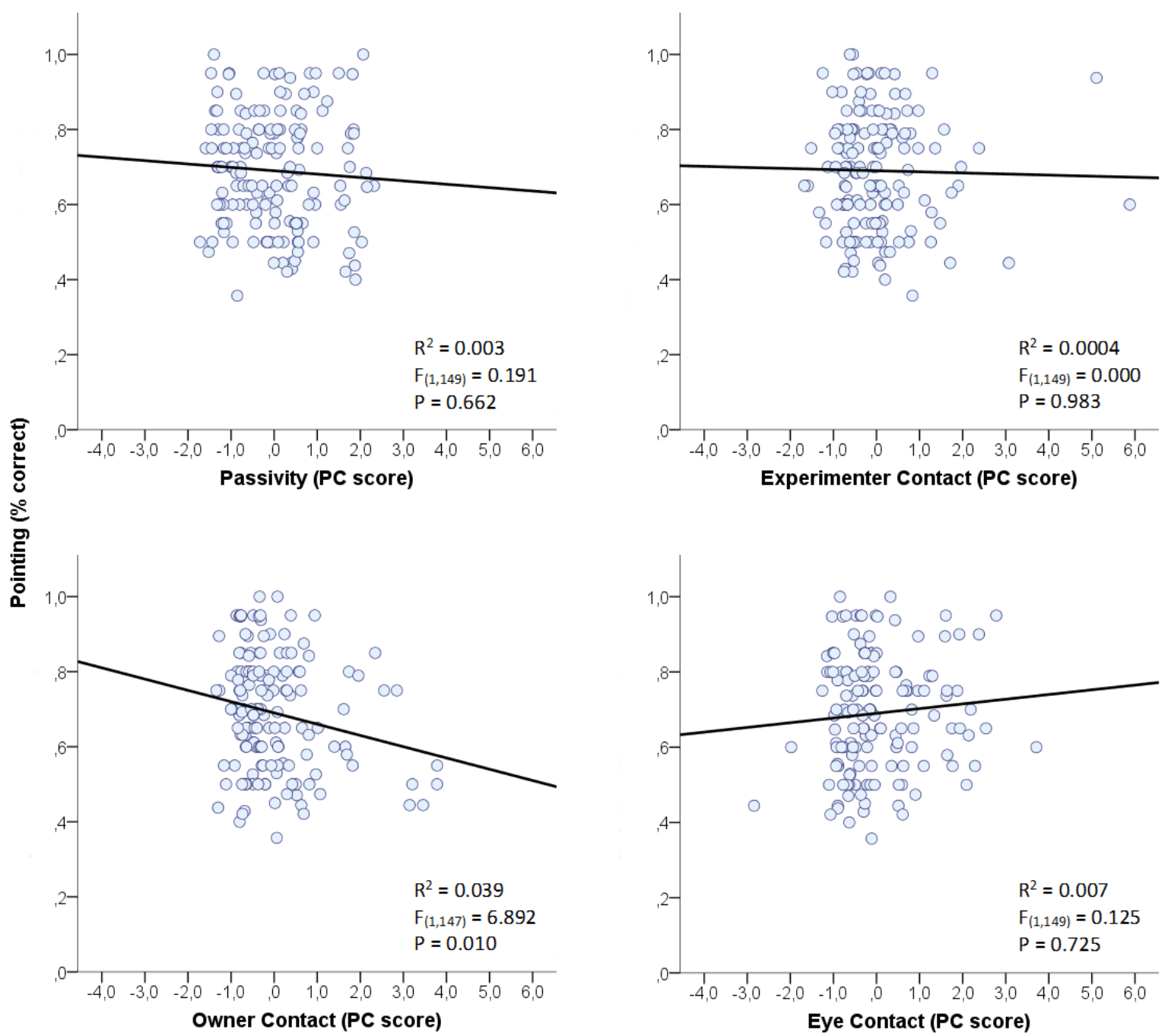

Figure 5. The relationship between percentage correct choices in the pointing test and the scores on each of the four problem-solving principal components Passivity, Experimenter Contact, Owner Contact and Eye Contact and $\mathrm{R}^{2}, \mathrm{~F}$ and $\mathrm{P}$ values for each. 
Table 1. Ethogram used in the behaviour analysis of the problem-solving test, adapted from Persson et al. (2015). Duration (dur.), frequency (freq.) or latency (lat.) was measured except for behaviours in the group Other.

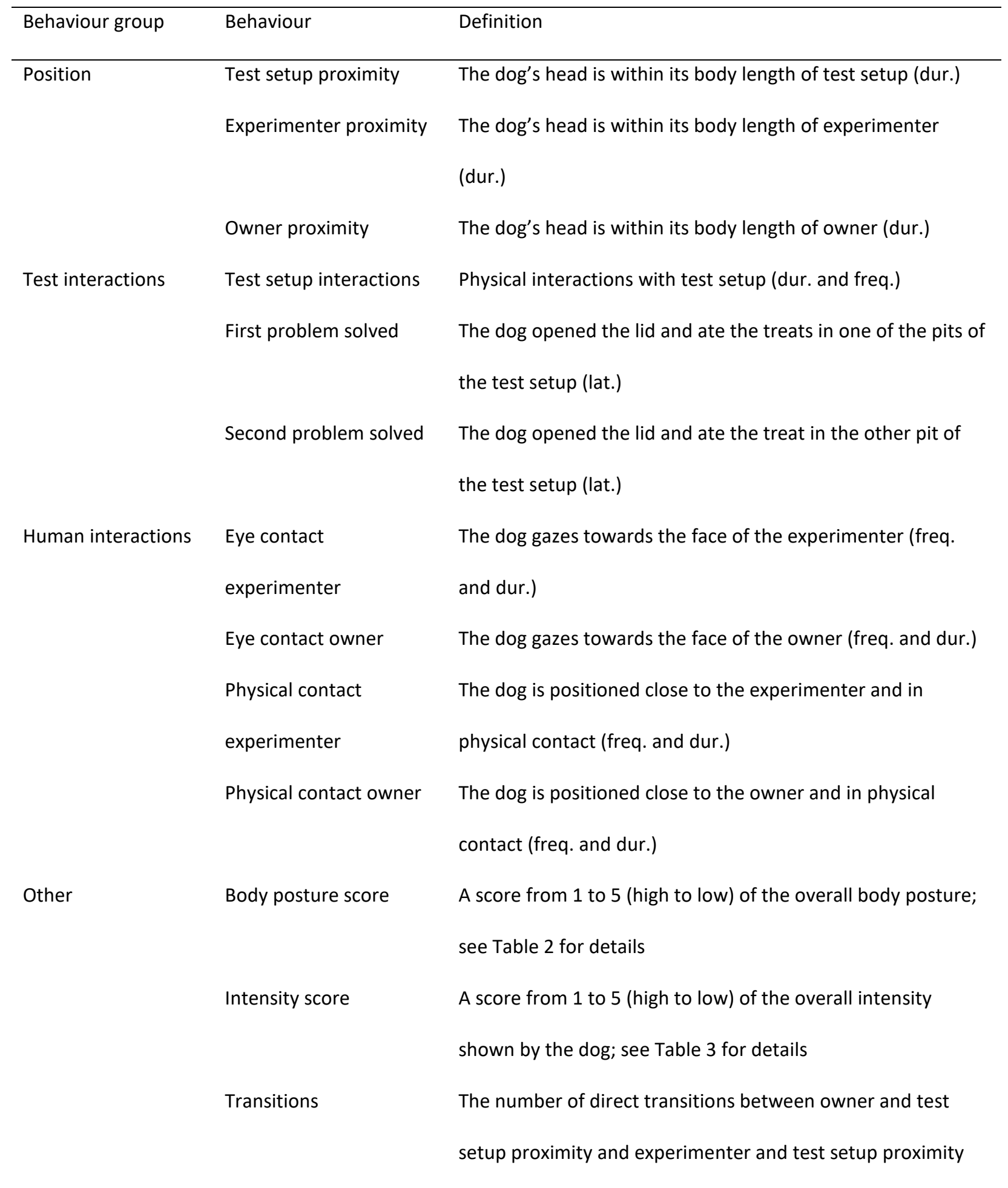


Table 2. Scoring criteria for the body posture of the dog during the problem-solving test.

\begin{tabular}{ll}
\hline Score & Description \\
\hline 1 & High wagging tail and high body position during the whole experiment; appears confident \\
2 & High wagging tail and/or high body position a majority of the time; appears fairly confident \\
3 & Neutral tail and/or body position a majority of the time; could in some cases appear as \\
& $\begin{array}{l}\text { somewhat insecure } \\
4\end{array}$ \\
& $\begin{array}{l}\text { Low tail and/or body position a majority of the time; can wag their tail; appears insecure and } \\
\text { Low tor body position a majority of the time; do not wag their tail; appears insecure }\end{array}$ \\
& and very cautious
\end{tabular}

Table 3. Scoring criteria for the overall intensity of the dog during the problem-solving test.

\begin{tabular}{ll}
\hline Score & Description \\
\hline $1 \quad$ Very intense: Moving all the time, energetically and with high pace; high frequency of paw use when \\
interacting with test setup \\
Intense: mostly moving at a high pace; intermediate frequency of paw use when interacting with the \\
test setup \\
Medium intensity: moving most of the time at a medium/low pace; medium frequency of paw use \\
$4 \quad$ Low intensity: low pace when moving, might be passive (standing or sitting) for some time
\end{tabular}


Table 4. Result from the principal component analysis on behavioural variables from the problemsolving test. Variables $>0.4$ (in bold) were considered of relevance to each component. PC1 was labelled Passive, PC2 Experimenter Contact, PC3 Owner Contact and PC4 Eye Contact.

\begin{tabular}{|c|c|c|c|c|}
\hline Behaviour variables & PC1 & PC2 & PC3 & PC4 \\
\hline Test setup interaction (dur.) &,- 786 &,- 256 & -361 &,- 238 \\
\hline Test setup proximity (dur.) &,- 765 &,- 273 &,- 394 &,- 217 \\
\hline First problem solved & ,743 & 222 & 076 &,- 018 \\
\hline Second problem solved & ,724 & 113 & 053 & 062 \\
\hline Intensity score & ,718 & -176 &,- 066 & -075 \\
\hline Body posture score & ,518 &,- 093 & -123 & -181 \\
\hline Physical contact experimenter (freq.) & ,022 & ,821 & 087 & 119 \\
\hline Experimenter proximity (dur.) & 280 & ,817 & 025 & 028 \\
\hline Physical contact experimenter (dur.) & ,034 & ,778 & 144 &,- 064 \\
\hline Transitions experimenter-test &,- 001 & ,683 & , 008 & 187 \\
\hline Physical contact owner (freq.) & 075 & ,090 & ,853 & 088 \\
\hline Physical contact owner (dur.) & 126 & ,094 & 822 & 011 \\
\hline Transitions owner-test &,- 061 & ,074 & 664 & 032 \\
\hline Owner proximity (dur.) & ,558 &,- 051 & ,594 & 200 \\
\hline Eye contact experimenter (freq.) &,- 077 & ,382 &,- 016 & ,824 \\
\hline Eye contact experimenter (dur.) &,- 003 & ,272 &,- 078 & 747 \\
\hline Eye contact owner (freq.) & 115 &,- 248 & ,390 & 672 \\
\hline Eye contact owner (dur.) & ,045 &,- 282 & 293 & ,416 \\
\hline$\%$ of variance explained & 19.46 & 16.89 & 15.47 & 11.73 \\
\hline
\end{tabular}


Supplementary Table S1. Mean \pm standard error on questionnaire questions for German Shepherd Dogs, Labrador retrievers and common and field type of Labrador retrievers. Significant differences between breeds and types in bold.

\begin{tabular}{|c|c|c|c|c|}
\hline & GSD & Labrador & Common & Field \\
\hline Owners first dog & Yes: 2 No: 30 & Yes: 16 No: 101 & Yes: 13 No: 44 & Yes: 3 No: 57 \\
\hline Lives with other dogs & Yes: 23 No: 9 & Yes: 75 No: 42 & Yes: 29 No: 28 & Yes: 46 No: 14 \\
\hline Hours alone & $2.500 \pm 0.456$ & $2.306 \pm 0.233$ & $2.518 \pm 0.267$ & $2.102 \pm 0.366$ \\
\hline Hours active & $2.328 \pm 0.178$ & $2.483 \pm 0.104$ & $2.373 \pm 0.165$ & $2.589 \pm 0.129$ \\
\hline Got for companion & $2.47 \pm 0.211$ & $2.700 \pm 0.127$ & $3.19 \pm 0.149^{b}$ & $2.22 \pm 0.184^{b}$ \\
\hline Got for training & $2.94 \pm 0.200$ & $3.15 \pm 0.099$ & $2.72 \pm 0.152^{b}$ & $3.56 \pm 0.316^{b}$ \\
\hline Often play & $3.16 \pm 0.169$ & $3.20 \pm 0.108$ & $3.33 \pm 0.138$ & $3.07 \pm 0.164$ \\
\hline Often correct & $2.59 \pm 0.184$ & $2.71 \pm 0.127$ & $2.56 \pm 0.197$ & $2.85 \pm 0.162$ \\
\hline Often reward & $3.56 \pm 0.134$ & $3.43 \pm 0.089$ & $3.49 \pm 0.125$ & $3.37 \pm 0.128$ \\
\hline Often train & $3.06 \pm 0.142^{a}$ & $3.30 \pm 0.097^{a}$ & $3.32 \pm 0.135$ & $3.29 \pm 0.141$ \\
\hline Often fetch & & & $1.74 \pm 0.191^{b}$ & $3.11 \pm 0.178^{b}$ \\
\hline
\end{tabular}



Supplementary Table S2. Correlation coefficients and significance values (presented as coefficient; P) for questionnaire questions versus problem-solving behaviours and the result from the pointing test. Significant results $(P<0.05)$ in bold.

\begin{tabular}{|c|c|c|c|c|c|}
\hline & Passivity & $\begin{array}{l}\text { Experimenter } \\
\text { Contact }\end{array}$ & $\begin{array}{l}\text { Owner } \\
\text { Contact }\end{array}$ & Eye Contact & $\begin{array}{l}\text { Pointing } \\
\text { (\% correct) }\end{array}$ \\
\hline $\begin{array}{l}\text { Hours alone } \\
\text { (n=149) }\end{array}$ & $-0.007 ; 0.933$ & $0.051 ; 0.539$ & $0.096 ; 0.244$ & $0.063 ; 0.443$ & $0.026 ; 0.754$ \\
\hline $\begin{array}{l}\text { Hours active } \\
(n=148)\end{array}$ & $-0.062 ; 0.458$ & $-0.194 ; 0.018$ & $-0.147 ; 0.075$ & $0.048 ; 0.565$ & $0.083 ; 0.136$ \\
\hline $\begin{array}{l}\text { Got for companion } \\
(n=149)\end{array}$ & $-0.077 ; 0.352$ & $-0.040 ; 0.628$ & $-0.187 ; 0.023$ & $-0.019 ; 0.820$ & $0.013 ; 0.878$ \\
\hline $\begin{array}{l}\text { Got for training } \\
(n=149)\end{array}$ & $-0.112 ; 0.175$ & $-0.118 ; 0.152$ & $0.049 ; 0.554$ & $0.015 ; 0.856$ & $0.127 ; 0.123$ \\
\hline $\begin{array}{l}\text { Often play } \\
(n=149)\end{array}$ & $-0.035 ; 0.674$ & $0.010 ; 0.906$ & $-0.162 ; 0.048$ & $0.016 ; 0.845$ & $-0.047 ; 0.572$ \\
\hline $\begin{array}{l}\text { Often correct } \\
(n=149)\end{array}$ & $-0.212 ; 0.009$ & $0.031 ; 0.797$ & $0.101 ; 0.218$ & $0.026 ; 0.757$ & $0.063 ; 0.445$ \\
\hline $\begin{array}{l}\text { Often reward } \\
(n=149)\end{array}$ & $0.062 ; 0.449$ & $-0.148 ; 0.071$ & $0.011 ; 0.890$ & $0.052 ; 0.531$ & $-0.019 ; 0.818$ \\
\hline $\begin{array}{l}\text { Often train } \\
(n=149)\end{array}$ & $-0.126 ; 0.125$ & $-0.022 ; 0,793$ & $-0.123 ; 0.136$ & $-0.042 ; 0.610$ & $-0.095 ; 0.251$ \\
\hline $\begin{array}{l}\text { Often fetch } \\
\text { (n=94, only }\end{array}$ & $0.113 ; 0.278$ & $0.029 ; 0.782$ & $0.056 ; 0.595$ & $0.194 ; 0.061$ & $0.218 ; 0.035$ \\
\hline Labrador) & & & & & \\
\hline
\end{tabular}

